\title{
Role of pregnancy associated plasma protein-A and doppler velocimetry in the assessment of fetomaternal outcome in high risk pregnancy
}

\author{
Asmita Kaundal $^{*}$, Usha Gupta ${ }^{1}$, Jayashree Bhattcharjee ${ }^{2}$
}

\begin{abstract}
${ }^{1}$ Department of Obstetrics and Gynaecology, Lady Hardinge Medical College, New Delhi, India
${ }^{2}$ Department of Biochemistry, Lady Hardinge Medical College, New Delhi, India
\end{abstract}

\author{
Received: 27 February 2019 \\ Accepted: 02 April 2019

\section{*Correspondence:} \\ Dr. Asmita Kaundal, \\ E-mail: drasmita_kaundal@yahoo.com
}

Copyright: (C) the author(s), publisher and licensee Medip Academy. This is an open-access article distributed under the terms of the Creative Commons Attribution Non-Commercial License, which permits unrestricted non-commercial use, distribution, and reproduction in any medium, provided the original work is properly cited.

\begin{abstract}
Background: The study aimed at defining the role of Pregnancy associated plasma protein-A (PAPP-A) and uterine artery doppler (Ut.A.PI) in the development of adverse pregnancy outcome (APO) in high risk pregnancies.

Methods: This was an observational study where 100 singleton pregnancies at high risk of development of APO, between 11 to $13+6$ weeks POG were enrolled. PAPP-A levels were measured at 11 to $13+6$ weeks POG and uterine artery doppler PI was measured at 20 weeks. Women were followed till delivery. Pregnancy outcome were seen and a cut off at which APO developed was derived.

Results: In this study women with lower mean PAPP-A $(0.75 \pm 0.19$ MOM versus $1.23 \pm 0.31 \mathrm{MOM})(\mathrm{p}<0.001)$ values and higher Ut.A.PI $(1.43 \pm 0.35 \mathrm{MOM}$ versus $0.99 \pm 0.25 \mathrm{MOM})(\mathrm{p}<0.001)$ developed APO. Cut off value for PAPP-A and Ut.A.PI was determined and was found to be $\leq 11.65 \mu \mathrm{g} / \mathrm{ml}(\leq 0.79 \mathrm{MoM})$ and $>1.42(>1.19 \mathrm{MoM})$ respectively which was higher than what is determined in other studies done on low risks populations thereby suggesting for an intervention or more meticulous observations at a higher cut offs.

Conclusions: PAPP-A and uterine artery doppler are already being used for the screening of preeclampsia in most of the countries but not for other adverse pregnancy outcomes. PAPP-A levels along with the uterine artery PI in predicting APO in high risk women has high negative predictive value. Hence can be uses as a screening method in high risk population whether they should be used for low risk population also needs further evaluation.
\end{abstract}

Keywords: Adverse pregnancy outcome, High risk pregnancy, PAPP-A, Uterine artery PI

\section{INTRODUCTION}

Pregnancy is defined as high risk when the probability of an adverse outcome for the mother or child is increased over and above the baseline risk for general population by the presence of one or more ascertainable risk factors. ${ }^{1}$ Maternal age, socioeconomic factors, medical conditions of the mothers, factors associated with uteroplacental insufficiency like pre-eclapmsia, eclampsia in present or previous pregnancies, previous history of intrauterine growth restriction, intrauterine death, preterm delivery, abruption are some of the risk factors which increases the maternal and fetal morbidity and mortality. Hence a need for screening modalities capable of detecting the highrisk women at early gestation so that women can be monitored more closely for better fetomaternal outcome. Various biomarkers like VEGFR-1, PLGF, PAPP-A, $\beta$ hCG have been studied alone or in combination with doppler indices. The most widely studied Doppler index is Pulsatility Index (PI= Peak Systolic Flow - End Diastolic Flow/Mean Flow). An increased Pulsatility Index is associated with an increased risk for preeclampsia and IUGR. ${ }^{2-4}$

PAPP-A (Pregnancy Associated Plasma Protein -A) is a trophoblast specific protein regulating IGF system and is 
predictive of a range of subsequent adverse pregnancy outcomes. $^{4}$ Low levels of PAPP-A are associated with poor pregnancy outcomes such as miscarriage, IUGR, PIH, IUD, premature delivery, etc. ${ }^{5}$ This study was done with the objective of combining first trimester screening with second trimester doppler indices and see their relation with the development of adverse outcome if any and for determining the cut off values for both PAPP-A and Ut.A.PI above which such complication should develop in high risk women.

\section{METHODS}

This was a descriptive observational study where 110 pregnant women with high risk pregnancies were enrolled between gestation 11-13+6 weeks from the antenatal clinic of Lady Harding Medical College and Associated Hospitals, New Delhi. Here high-risk pregnancy was defined as one with preeclampsia, eclamspsia, abruption, intrauterine growth restriction, intrauterine death, preterm birth in present or previous pregnancies. Women with multifetal pregnancies, chromosomal abnormalities, congenital abnormalities, heart disease, smokers, history of threatened abortion in present pregnancy and those who did not consent were excluded from the study. Detailed history of present or past pregnancy, any medical or surgical illness, treatment, substance abuse, past medical and surgical history and family history was taken. Gestational age was calculated from last menstrual period and confirmed from the first trimester ultrasound. Through general physical and antenatal examination was carried out. Baseline investigations like complete blood count, blood sugars, liver and kidney function tests were done. Obstetric ultrasound was done to calculate the gestational age, rule out any congenital malformation and any complications of first trimester like subchorionic bleed and missed abortion. Special investigation like fundus examination, 24 hours urine protein were done wherever indicated. Blood samples for the estimation of PAPP-A was taken $11-13+6$ weeks of gestation by venipuncture in plain vials, which was then allowed to clot and serum was separated by centrifugation $(1500 \mathrm{rpm})$ at room temperature. Specimens were stored at -20 degree centigrade. All reagents and specimen were allowed to stabilize at room temperature before test. All the reagents were mixed. All standard samples and controls were run under duplication. Microtiter wells were secured in the frame holder. 10 microlitres of each standard, control and sample were dispensed in each well with new disposable tips. 100 microlitres of Assay Buffer was added to each well and mixed thoroughly for 10 seconds, incubated for 30 minutes at room temperature and then briskly the contents of the well were shaken out. Wells were rinsed with dilute wash solution (400 microlitres). 100 microlitres of enzyme conjugate was added and incubated for 30 minutes at room temperature. The contents were shaken out and washed thrice with wash solution. 100 microlitres of substrate solution was added to each well, incubated for 15 minutes. 50 microlitres of stop solution was added to each well. Absorbance for each well was determined at $450 \pm 10 \mathrm{~nm}$ with the microplate reader within 10 minutes. A standard curve was constructed and corresponding concentration from each curve was determined using mean absorbance (Figure 1) (Table 1).

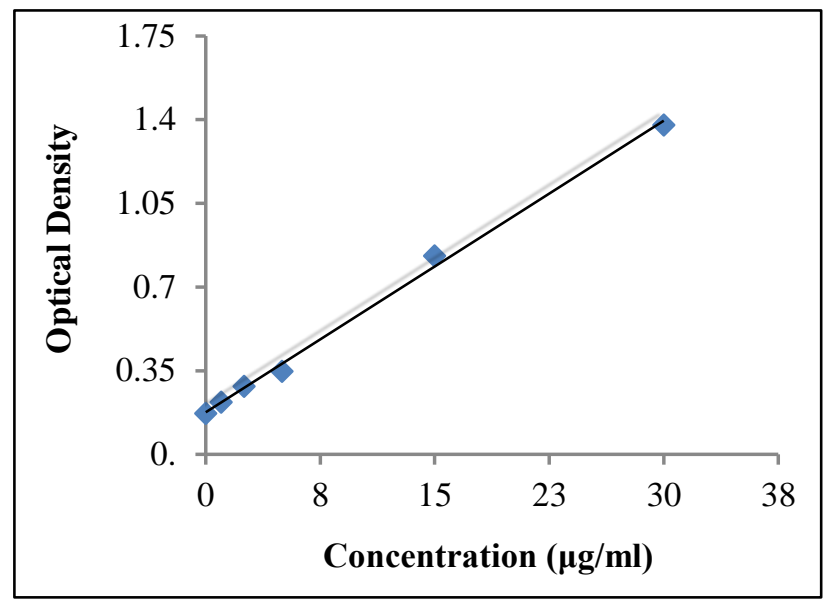

Figure 1: Standard curve for PAPP-A $(\mu \mathrm{g} / \mathrm{ml})$.

Table 1: Standard concentration of pregnancy associated plasma protein-A against optical density.

\begin{tabular}{|ll|}
\hline Conc. $(\mu \mathrm{g} / \mathrm{ml})$ & OD \\
\hline 0 & 0.172 \\
\hline 1 & 0.219 \\
\hline 2.5 & 0.285 \\
\hline 5 & 0.347 \\
\hline 15 & 0.831 \\
\hline 30 & 1.378 \\
\hline
\end{tabular}

For all these women Uterine Artery Doppler was performed at 20 weeks of gestation. Flow velocity waveforms of the right and left uterine arteries were imaged with patient in semi-recumbent position and uterine artery identified on a longitudinal scan, lateral to the uterus where scan show the bifurcation of the common iliac artery. Recordings were made at the point where the uterine artery and the external iliac appear to cross each other. Following this, mean PI in uterine artery was calculated and presence/absence of notch was noted. In those women who had abnormal Doppler findings, repeat study was done after one month and subsequently as per requirement, till delivery. Women were followed till delivery to know the outcome.

Outcome was recorded in terms of development of any complication like Preeclampsia, eclampsia, abruption, intrauterine growth restriction, intrauterine death, preterm deliveries.

According to the outcome the patients were divided into two groups. Women who did not develop any complication were assigned group $\mathrm{A}$ and those who developed complications were assigned group B. 


\section{RESULTS}

In the study 2 patients $(1.81 \%)$ discontinued after initial sampling for PAPP-A because of abnormal $\mathrm{Nt}-\mathrm{Nb}$ scan and were referred to fetal medicine unit for further evaluation. 1 patient $(0.9 \%)$ had spontaneous abortion at 12 weeks. 7 patients $(6.36 \%)$ were lost during follow up. So, total 100 patients were observed for the final outcome.

Majority of the women who were enrolled in the study were between 26-30 years of age (41\%) with mean age of 25.81 \pm 4.35 . Most women had normal BMI $(90 \%)$, where mean BMI was 22.96 \pm 2.22 . Around $10 \%$ were primigravida and $90 \%$ multigra-vida $(3 \%$ grand multipara).

This study enrolled only high risk women where most common risk factor was raised BP in previous pregnancies $24 \%$ followed by $19 \%$ with preterm births, $18 \%$ with diabetics, $16 \%$ had history of raised BP at enrolment, $11 \%$ had previous intrauterine deaths, $5 \%$ had fetal growth restriction. Around $7 \%$ of the patients had more than one risk factors. Mean PAPP-A levels of the study population was $13.56 \pm 4.61 \mu \mathrm{g} / \mathrm{ml}(1.07 \pm 0.36 \mathrm{MoM})$ and mean Uterine artery PI was $1.29 \pm 0.4(1.01 \pm 0.32$ MoM) [(Figure 2 (A and B)].

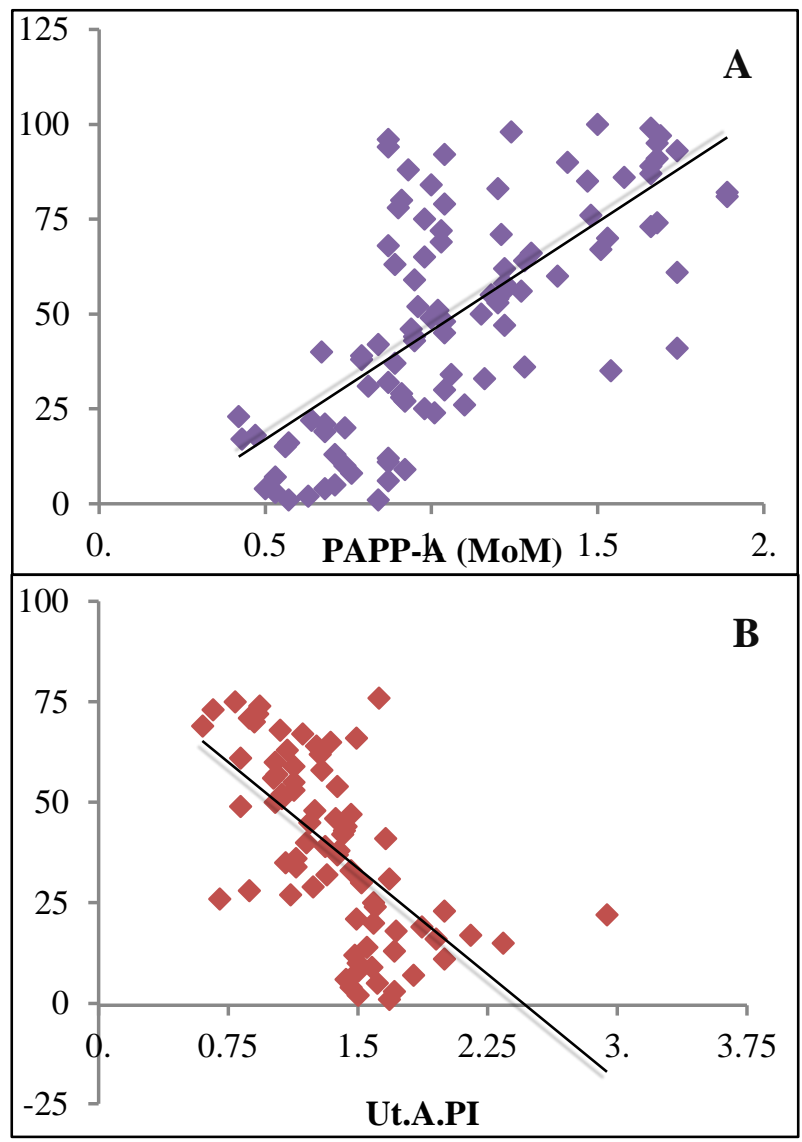

Figure 2: (A) Scatter plot diagram showing PAPP-A levels of patients in MoM, (B) Scatter-plot diagram showing uterine artery PI in patients in MoM.
Most of the women delivered at term (79\%), only $21 \%$ delivered before 36 completed weeks (mean GA $37.37 \pm 1.9$ wks.). Around $84 \%$ went into spontaneous labour, $16 \%$ were induced $(2 \%$ for IUD with preeclampsia and $12 \%$ for uncontrolled BP with or without SGA babies). Out of all $90 \%$ of the women had normal vaginal delivery of which $67.7 \%$ were at term at or after 37 completed weeks, $16 \%$ were preterm deliveries. Around $2 \%$ of the preterm deliveries were due to IUD at 28 weeks. Out of those who required LSCS for various reasons $70 \%$ were at term and $30 \%$ were preterm caesarean sections. $6 \%$ of the caesarean sections were done for fetal distress with or without meconium, $3 \%$ for non-progress of labor and $1 \%$ for second stage arrest. Around $4 \%$ of the babies were born with birth weight of $<1.5 \mathrm{~kg}$ out of which 2 were those who had intrauterine death at 28 and 30 weeks, $5 \%$ were between $1.5-1.9 \mathrm{~kg}$, $20 \%$ between $2-2.4 \mathrm{~kg}$ and $71 \%$ of the of the babies had birth weight above $2.5 \mathrm{~kg}$.

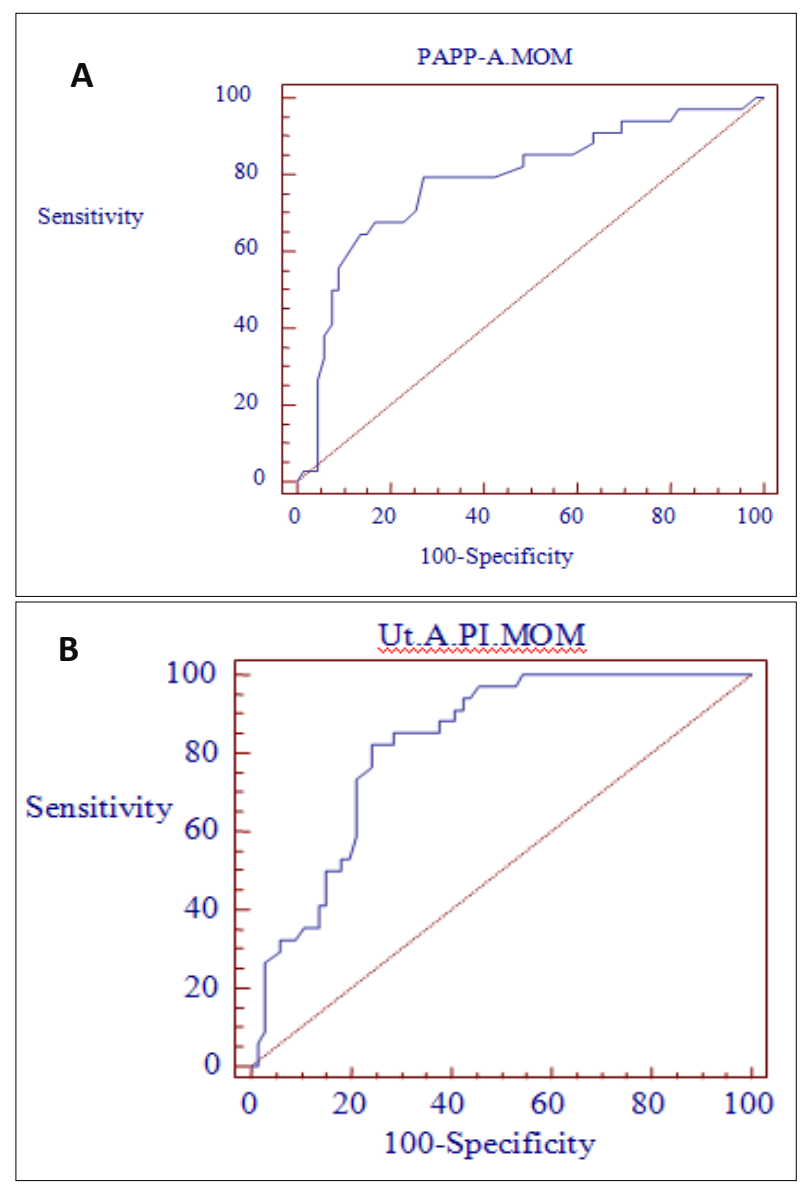

Figure 3: (A) Receiver-operator curve for determination of cut-off valves for PAPP-A and

Ut.A.PI, (B) Receiver-operator curve for determination of cut-off valves for PAPP-A and Ut.A.PI.

In this study $66 \%$ of the women had normal outcome with no maternal or fetal complications and $34 \%$ had one or more complications either in fetus or mother. Around $20 \%$ developed gestational hypertension controlled on 
antihypertensive, $14 \%$ developed preeclampsia. Out of the $14 \%$ women developing preeclampsia $4 \%$ had early PE before 34 weeks) and rest $10 \%$ developed Late PE (after 34 weeks). Total 69\% babies were born without any complications, $22 \%$ were small for gestational age, $11 \%$ were preterm, and 2 were intrauterine deaths (Table 2). When PAPP-A levels were related to the pregnancy outcome the values were significantly lower in those developing adverse outcome than those with normal outcome i.e.9.52 $\pm 2.53 \mu \mathrm{g} / \mathrm{ml}, \quad(0.75 \pm 0.19 \mu \mathrm{MoM})$ vs $15.64 \pm 4.03 \mu \mathrm{g} / \mathrm{ml}(1.23 \pm 0.31) \mathrm{p}$-value $<0.001$ (Table 3 ).
From the receiver-operator curve the cut off value of $\leq 11.65 \mu \mathrm{g} / \mathrm{ml} \quad(\leq 0.79 \mathrm{MoM})$ was derived for the prediction of adverse pregnancy outcome (APO) in the high risk women (Figure 3, A). Similarly the cut off value for Uterine artery PI was derived which was $>1.42(>1.19$ MoM) (Figure 3, B).

Uterine artery PI was observed to be higher in the women with APO when compared to those with normal outcome. i.e. $1.61 \pm 0.80(1.43 \pm 0.35 \mathrm{MoM})$ vs $1.12 \pm 0.29 \mu \mathrm{U} / \mathrm{L}$ $(0.99 \pm 0.25 \mathrm{MoM}) \mathrm{P}$-value $<0.001$.

Table 2: Demographic profile of the women enrolled in the study.

\begin{tabular}{|c|c|}
\hline Demographic factor & $\mathrm{n}=\mathbf{1 0 0}$ \\
\hline Mean Age & $25.81 \pm 4.35( \pm \mathrm{SD})$ \\
\hline Mean BMI & $22.96 \pm 2.22( \pm \mathrm{SD})$ \\
\hline \multicolumn{2}{|l|}{ Gravidity } \\
\hline Primigravida & $10 \%$ \\
\hline Multigravida & $90 \%$ \\
\hline \multirow{7}{*}{ High risk factors } & Raised BP in previous pregnancies $-16 \%$ \\
\hline & $\mathrm{H} / \mathrm{O}$ preterm births- $19 \%$ \\
\hline & $\mathrm{H} / \mathrm{O}$ Small for gestational age babies $-5 \%$ \\
\hline & H/O Intrauterine fetal deaths- 11 \\
\hline & Bad obstetrics history- $24 \%$ \\
\hline & Diabetes - $18 \%$ \\
\hline & Raised Bp at presentation- $16 \%$ \\
\hline Mean PAPP-A level & $13.56 \pm 4.61 \mu \mathrm{g} / \mathrm{ml}(1.07 \pm 0.36 \mathrm{MoM})$ \\
\hline Mean Uterine artery PI & $1.29 \pm 0.4(1.01 \pm 0.32 \mathrm{MoM})$ \\
\hline Mean gestational age at delivery & $37.37 \pm 1.9$ wks. \\
\hline Normal vaginal delivery & $90 \%$ \\
\hline LSCS & $10 \%$ \\
\hline \multirow{5}{*}{ Maternal Outcome } & Normal $-66 \%$ \\
\hline & Abnormal-34\% \\
\hline & PE-14\% \\
\hline & Early PE-10\% \\
\hline & Late PE - $4 \%$ \\
\hline \multirow{5}{*}{ Fetal outcome } & Normal- $69 \%$ \\
\hline & Abnormal-31\% \\
\hline & SGA-22\% \\
\hline & Preterm-11\% \\
\hline & IUD-2\% \\
\hline
\end{tabular}

On further analysis when the mean PAPP-A levels and mean Uterine artery PI was related to different outcomes individually it was seen that PAPP-A levels were lowest in the women who had developed preeclampsia with small for gestational age baby $7.24 \pm 1.31 \mu \mathrm{g} / \mathrm{ml}$ $(0.57 \pm 0.10 \mathrm{MOM})$ than those with preeclampsia alone $7.30 \pm 1.33 \mu \mathrm{g} / \mathrm{ml} \quad(0.57 \pm 0.11 \mathrm{MoM}) \quad$ or $\quad$ SGA alone $10.84 \pm 1.64 \mu \mathrm{g} / \mathrm{ml}(0.85 \pm 0.13 \mathrm{MOM})$. Mean PAPP-A was lower in those who delivered preterm babies $10.19 \pm 4.72 \mu \mathrm{g} / \mathrm{ml}(0.80 \pm 0.38 \mathrm{MOM})$ than in those who had term deliveries $14.29 \pm 4.34 \mu \mathrm{g} / \mathrm{ml}(1.13 \pm 0.74 \mathrm{MOM})$ the difference was statistically significant $\mathrm{p}$-value $<0.001$. With respect to the birth weight PAPP-A levels were found to be $9.21 \pm 2.29 \mu \mathrm{g} / \mathrm{ml}(0.73 \pm 0.19 \mathrm{MOM})$ in those with SGA babies as compared to those with no SGA $15.09 \pm 4.32 \mu \mathrm{g} / \mathrm{ml} \quad(1.18 \pm 0.33 \mathrm{MOM})$ p-value $<0.001$ (Table 4). 
Table 3: Combined pregnancy associated plasma protein-A and uterine artery pulsatility index in relation to pregnancy outcome.

\begin{tabular}{|lll|}
\hline Outcome $(\mathrm{n}=100)$ & PAPP-A & UT.A.PI \\
\hline PE alone $(\mathrm{n}=4)$ & $7.30 \pm 1.33 \mu \mathrm{g} / \mathrm{ml}(0.57 \pm 0.11 \mathrm{MOM})$ & $2.03 \pm 0.08(1.58 \pm 0.32 \mathrm{MOM})$ \\
\hline SGA alone $(\mathrm{n}=12)$ & $10.84 \pm 1.64 \mu \mathrm{g} / \mathrm{ml}(0.85 \pm 0.13 \mathrm{MOM})$ & $1.53 \pm 0.21(1.19 \pm 0.16 \mathrm{MOM})$ \\
\hline PE+SGA $(\mathrm{n}=10)$ & $7.24 \pm 1.31 \mu \mathrm{g} / \mathrm{ml}$ & $1.83 \pm 0.3(1.42 \pm 0.22 \mathrm{MOM})$ \\
\hline Term birth $(\mathrm{n}=87)$ & $(0.57 \pm 0.10)$ & $1.23 \pm 0.80(0.97 \pm 0.62 \mathrm{MOM})$ \\
\hline Preterm birth $(\mathrm{n}=13)$ & $14.29 \pm 4.34 \mu \mathrm{g} / \mathrm{m}(10.80 \pm 0.38 \mathrm{MOM})$ & $1.50 \pm 0.78(1.50 \pm 0.78 \mathrm{MOM})$ \\
\hline
\end{tabular}

Table 4: Corelation of pregnancy associated plasma protein-a levels and uterine artery pulsatility index to different pregnancy outcome.

\begin{tabular}{|llll|}
\hline Parameters & $\begin{array}{l}\text { Pregnancy Outcome } \\
\text { Group A* } \\
(\mathbf{n = 6 6})\end{array}$ & $\begin{array}{l}\text { Group B\# } \\
(\mathbf{n = 3 4 )}\end{array}$ & P value \\
\hline PAPP-A $\mu \mathrm{g} / \mathrm{ml}(\mathrm{MoM})$ & $15.64 \pm 4.03(1.23 \pm 0.31 \mathrm{MOM})$ & $9.52 \pm 2.53(0.75 \pm 0.19 \mathrm{MOM})$ & $<0.001^{* *}$ \\
\hline Ut.A.PI at 20 weeks $(\mathrm{MoM})$ & $1.12 \pm 0.29(0.99 \pm 0.25 \mathrm{MOM})$ & $1.61 \pm 0.40(1.43 \pm 0.35 \mathrm{MOM})$ & $<0.001^{* *}$ \\
\hline
\end{tabular}

Table 5: Predictive potential of pregnancy associated plasma protein-A and uterine artery pulsatility index for adverse pregnancy outcome.

\begin{tabular}{|lllllllll|}
\hline Parameters & Cut-off & Sensitivity & Specificity & PPV & NPV & Accuracy & AUC & P value \\
\hline PAPP-A $\mu \mathrm{g} / \mathrm{ml}(\mathrm{MoM})$ & $\leq 11.65(\leq 0.79)$ & 85.29 & 83.33 & 72.50 & 91.67 & 84.00 & 0.910 & $<0.001^{* *}$ \\
\hline Ut.A.PI at 20 wks $(\mathrm{MoM})$ & $>1.42(>1.19)$ & 77.78 & 87.88 & 77.78 & 87.88 & 84.31 & 0.869 & $<0.001^{* *}$ \\
\hline PAPP-A And Ut.A. PI & - & 91.18 & 74.24 & 64.58 & 94.23 & 80.00 & - & $<0.001^{* *}$ \\
\hline
\end{tabular}

Similar analysis was done for uterine artery PI. Uterine artery PI was found to be higher in those with PE alone $2.03 \pm 0.08(1.58 \pm 0.32 \mathrm{MOM})$ than in those with $\mathrm{PE}$ with SGA $1.83 \pm 0.3(1.42 \pm 0.22 \mathrm{MOM})$ or SGA alone $1.53 \pm 0.21(1.19 \pm 0.16 \mathrm{MOM}) \mathrm{p}$-value $=0.00$.Those who developed SGA babies had Ut.A.PI 1.67 \pm 0.28 $(1.30 \pm 0.11 \mathrm{MOM})$ as compared to those with no SGA $1.64 \pm 0.36(0.91 \pm 0.36)$ p-value $<0.001$ which was significant statistically. Mean uterine artery PI was significantly higher in those who later had IUD 1.74 \pm 0.19 $(1.36 \pm 0.15 \mathrm{MoM})$. Mean uterine artery PI was higher in those who delivered prematurely before 3 weeks $1.50 \pm 0.78(1.17 \pm 0.58 \mathrm{MOM})$ as compared to those delivering after 36 weeks $1.23 \pm 0.80(0.97 \pm 0.62 \mathrm{MOM}) \mathrm{P}$ value $=0.004$ (Table 4).

When both the PAPP-A and uterine artery PI were used for prediction of APO it was seen that PAPP-A alone was $85.29 \%$ sensitive, $83.33 \%$ specific, with $72.5 \%$ positive Predictive value and $91.6 \%$ and negative predictive value.

Uterine artery PI alone was $77.78 \%$ sensitive, $87.88 \%$ specific, with $78 \%$ positive predictive value and $87.8 \%$ negative predictive value. However, when both the tests were combined the sensitivity in-creased to $91.18 \%$, with marginal decrease in specificity and PPV to $74.24 \%$ and $64.58 \%$ respectively. There was increase in the negative predictive value to $94.23 \%$ with marginal decrease in the accuracy from $84 \%$ for both PAPP-A and uterine artsy PI alone to $80 \%$ when both were used together. Area under the curve for uterine artery PI was 0.869 and that for PAPP-A was 0.910 (Table 5).

\section{DISCUSSION}

Fundamental objective of prenatal care is to detect the women at high risk of developing adverse pregnancy outcome as early as possible preferably in first trimester of pregnancy so that early interventions can be done to reduce the perinatal morbidity and mortality.

Pregnancy associated plasma protein A is one of the trophoblast derived placental protein, low levels of PAPP-A were found helpful in prediction of adverse pregnancy outcome. In the present study this was found that low PAPP-A levels in the first trimester are associated with APO later in the pregnancy. In the present study the mean PAPP-A was $13.56 \pm 4.61 \mu \mathrm{g} / \mathrm{ml}$ $(1.07 \pm 0.36 \mathrm{MoM})$ which is higher than the studies done earlier by Pilalis et al. which could be because of unselected population being used by the researcher while present study was done on high risk patients only. ${ }^{6} \mathrm{~A}$ cut off value of $\leq 11.65 \mu \mathrm{g} / \mathrm{ml}(\leq 0.79 \mathrm{MoM})$ was determined above which the pregnancies were considered to have one or more APO. Author in his study observed $28 \%$ APO while here in this study the APO was $34 \%$ which was expected as the study was done on high risk women. When the study was analyzed it was seen that the women who had normal pregnancy outcome had higher mean 
PAPP-A levels then those who later developed adverse outcome. When the PAPP-A levels were analyses within the group with APO the levels were significantly lower in those who developed preeclampsia (0.57) then those who do not have PE (1.04MoM). PAPP-A levels were lower in those with early onset PE (0.49 MoM) than with Late onset PE. $(0.64 \mathrm{MoM})(\mathrm{p}<0.001)$. Similar trends were seen by the other authors in this study (Spencer et al.) (Table 6). ${ }^{7}$ PAPP-A levels were lower in the pregnancies who had preterm deliveries and small for gestational age.

Table 6: Comparison of pregnancy associated plasma protein-A levels in preeclampsia in various studies.

\begin{tabular}{|c|c|c|c|c|c|c|c|}
\hline \multirow{3}{*}{ Study } & \multirow{3}{*}{ Sample size } & \multicolumn{4}{|c|}{ PAPP-A (MoM) } & \multicolumn{2}{|l|}{ P-value } \\
\hline & & \multirow{2}{*}{$\begin{array}{l}\text { Unaffected } \\
\text { group }\end{array}$} & \multicolumn{3}{|c|}{ Group B } & \multirow{2}{*}{ Early PE } & \multirow{2}{*}{ Late PE } \\
\hline & & & PE* & Early PE & Late PE & & \\
\hline Poon et $\mathrm{al}^{25}$ & $\begin{array}{l}8051 \\
(\mathrm{LR})^{* *}\end{array}$ & 1.002 & - & 0.555 & 0.999 & $<0.001$ & $=0.03$ \\
\hline Spencer et $\mathrm{al}^{48}$ & $\begin{array}{l}5867 \\
(\mathrm{LR})\end{array}$ & 1.004 & 0.89 & 0.89 & 0.98 & $=0.042$ & 0.557 \\
\hline Poon et $\mathrm{al}^{51}$ & $\begin{array}{l}8366 \\
(\mathrm{LR})\end{array}$ & 1.01 & - & 0.58 & 0.90 & $=0.001$ & $<0.001$ \\
\hline Present study & $100(\mathrm{HR}) * * *$ & 1.2 & 0.57 & 0.49 & 0.64 & $<0.001$ & $<0.001$ \\
\hline
\end{tabular}

*Preeclampsia, **Low risk, *** High risk

Table 7: Comparison of uterine artery pulsatility index in preeclampsia in various studies.

\begin{tabular}{|c|c|c|c|c|c|c|c|}
\hline \multirow{3}{*}{ Study } & \multirow{3}{*}{ Sample size } & \multicolumn{4}{|c|}{ UT.A.PI (Median MoM) } & \multicolumn{2}{|l|}{ P-value } \\
\hline & & \multirow{2}{*}{ Group A } & \multicolumn{3}{|c|}{ Group B } & \multirow{2}{*}{ Early PE } & \multirow{2}{*}{ Late PE } \\
\hline & & & PE* & Early PE & Late PE & & \\
\hline Poon et al. ${ }^{25}$ & $\begin{array}{l}8051 \\
(\mathrm{LR})^{* * *}\end{array}$ & 1.007 & - & 1.498 & 1.189 & $<0.001$ & $<0.001$ \\
\hline Spencer et $\mathrm{al}^{48}$ & $\begin{array}{l}5867 \\
\text { (LR) }\end{array}$ & 1.00 & 1.60 & 1.70 & 1.36 & $<0.001$ & $<0.001$ \\
\hline Poon et al. ${ }^{51}$ & $\begin{array}{l}8366 \\
\text { (LR) }\end{array}$ & 1.01 & & 1.60 & 1.23 & $<0.0001$ & $<0.0001$ \\
\hline Present study & $100(\mathrm{HR})^{* * *}$ & 0.89 & 1.38 & 1.44 & 1.32 & $<0.001$ & $<0.001$ \\
\hline
\end{tabular}

*Preeclampsia, **Low risk, *** High risk

Uterine artery doppler is another good method of the prediction of APO. In normal pregnancy there is placental trophoblastic invasion of spiral arteries in the decidua which starts at conception and the process in completed by 22 weeks of gestation. This results in conversion of high resistance arteries to low resistance and high flow state and this is reflected as decreasing uterine artery PI on doppler with increasing gestation. ${ }^{2,8}$ Herein lies the importance of performing Ut. A.PI. at uniform period of gestation or to establish cut off for that specific period of gestation so that results can be interpreted and compared globally.

Uterine artery Doppler was done at 20 weeks of gestation as most of the patients also come for anomaly scan at this time so it's convenient for the doctor as well as the patient. A cut-off value of $>1.42(>1.19 \mathrm{MoM})$ was determined. Overall mean uterine artery PI for all patients was $1.29 \pm 0.04(1.01 \pm 0.32 \mathrm{MoM})$ in the present study. This was lower than the mean uterine artery PI of 1.71 observed by Pilalis et al. in their study. ${ }^{6}$ The higher PI reported by the authors might be due to the fact that they performed uterine artery PI at much earlier period of gestation (11-13+6weeks). In the present study the mean Ut.A.PI was higher in the women with APO $(1.61 \pm 0.40)$, than those who were unaffected $(1.12 \pm 0.29)$. Similar to the experience of the present study, Poon et al., Spencer et al. and Pilalis et al., Albaiges et al., Lees et al., Yu et al. in their studies all the authors observed increased Ut.A.PI. in women who subsequently developed adverse pregnancy outcome. ${ }^{7,6,9-13}$ Mean Uterine artery PI was higher in those who had PE $1.87 \pm 0.39(1.46 \pm 0.31 \mathrm{MoM})$ than those who were unaffected $1.19 \pm 0.32$ $(0.93 \pm 0.25 \mathrm{MoM})$. Median PI was higher being 1.44 MoM in early PE as against $1.30 \mathrm{MoM}$ in late onset preeclampsia. The observation was similar when compared with the studies done by the other authors (Spencer et al). ${ }^{7}$ (Table 7). Uterine artery PA was higher in those with SGA babies than who delivered normal babies $(1.67 \pm 0.28(1.30 \pm 0.11)$ VS $1.64 \pm 0.36(0.91 \pm 0.36$ 
MoM). In the present study, after analyses of the results it was observed that low level of PAPP-A in early gestation is associated with adverse pregnancy outcome at later gestation. Predictive efficacy of PAPP-A alone for adverse pregnancy outcome had sensitivity of $85.29 \%$, specificity of $83.33 \%$, accuracy of $84 \%$, positive predictive value of $72.50 \%$ and negative predictive value of $84 \%$. ROC curve was generated and Area Under the Curve was determined as 0.91 which is considered excellent. (0.9-1.0- excellent, 0.8-0.9-good, 0.7-0.8-fair, 0.8-0.7-poor,0.5-0.6-fair). Similarly when Uterine artery PI was analyzed alone for its predictive efficacy for adverse pregnancy outcome it had sensitivity of $77.78 \%$, specificity of $87.88 \%$, accuracy of $84.31 \%$, positive predictive value of $77.78 \%$ and negative predictive of $87.88 \%$. Area under the curve was found to be 0.87 which is considered good (Table 8).

Table 8: Comparison of predictive efficacy of pregnancy associated plasma protein -A combined with uterine artery pulsatility index in various studies.

\begin{tabular}{|c|c|c|c|c|c|c|c|c|c|}
\hline Study & $\begin{array}{l}\text { Sample } \\
\text { size }\end{array}$ & Parameters & Sn & Sp & PPV & NPV & Ac. & AUC & $P$ value \\
\hline \multirow{3}{*}{$*$ Spencer et al. ${ }^{48}$} & \multirow{3}{*}{$\begin{array}{l}5867 \\
\text { (LR) }\end{array}$} & PAPP-A & $24 \%$ & - & - & - & - & 0.56 & 0.076 \\
\hline & & UT.A.PI & $73 \%$ & - & - & & - & 0.59 & $<0.001$ \\
\hline & & Combined & $76 \%$ & - & - & - & - & 0.82 & $<0.001$ \\
\hline \multirow{3}{*}{ *Poon et al. ${ }^{25}$} & \multirow{3}{*}{$\begin{array}{l}8051 \\
\text { (LR) }\end{array}$} & PAPP-A & - & - & - & - & - & 0.79 & \multirow{3}{*}{$<0.001$} \\
\hline & & UT.A.PI & - & - & - & - & - & 0.81 & \\
\hline & & Combined & - & - & - & - & - & 0.81 & \\
\hline \multirow{3}{*}{ Spencer et.al ${ }^{52}$} & \multirow{3}{*}{$\begin{array}{l}4390 \\
\text { (LR) }\end{array}$} & PAPP-A & $14.1 \%$ & - & - & - & - & - & - \\
\hline & & UT.A.PI & $54.7 \%$ & - & - & - & - & - & - \\
\hline & & Combined & $62.1 \%$ & - & - & - & - & - & - \\
\hline \multirow{3}{*}{ Present study } & \multirow{3}{*}{$\begin{array}{l}100 \\
\text { (HR) }\end{array}$} & PAPP-A & 85.29 & 83.33 & 72.50 & 91.67 & 84.00 & 0.91 & $<0.001$ \\
\hline & & UT.A.PI a & 77.78 & 87.88 & 77.78 & 87.88 & 84.31 & 0.87 & $<0.001$ \\
\hline & & Combined & 91.18 & 74.24 & 64.58 & 94.23 & 80.00 & - & $<0.001$ \\
\hline
\end{tabular}

When both the parameters were combined together sensitivity of the test increased to $91.18 \%$ and NPV $94.23 \%$. However, there was marginal decrease in the specificity, PPV and accuracy. In study of Spencer et al. on combined use of PAPP-A and Uterine Artery Doppler in prediction of adverse pregnancy outcome, the authors observed that when the test is analyzed with regard to pre-eclampsia its sensitivity for prediction for preeclampsia was $54.7 \%$ when Uterine artery was used alone and it increased to $60 \%$ when serum PAPP-A was combined with the Uterine Artery Doppler. ${ }^{14}$ In the studies done by Spencer et al. and Pilalis et al., the authors also observed that the combined use of both the parameters improves the predictive efficacy for adverse pregnancy outcome. In the study done by Poon et al. detection rate of early pre-eclampsia was $37.4 \%$ when maternal factors were analyzed alone, it improved to $78 \%$ with addition of Ut.A. Doppler and it increased further to $84 \%$ when serum PAPP-A levels were added to the analysis. ${ }^{14,6,9}$ A study published in 2016 by Kumar Manisha el al. has seen that combining the two tests increases the sensitivity to $62 \%$ (32\% when PAPP-A was used alone or $4 \%$ when Ut. A. PI was used alone). ${ }^{15}$ NPV also increased to $93 \%(87 \%)$ for PAPP-A alone and $84 \%$ for Ut.A.PI alone). From the results of the present study, it was found that PAPP-A levels alone or Uterine Artery Doppler alone can be used in the prediction of adverse pregnancy outcome in high risk women as the sensitivity of either test was found to be high. The combined use of two parameters further improves the sensitivity and negative predictive value.

The problem of compliance and logistics however, is a real one when both parameters PAPP-A and Uterine Artery Doppler are used. Therefore when the study population is a high risk one, any of the two parameters may be used with almost equal predictive efficacy for adverse pregnancy outcome. Thus, the women may be screened by PAPP-A in the first trimester if she presents for routine first trimester scan or she may be screened with Ut.A. Doppler if she presents for Level II ultrasound for fetal anomaly scan. As the present study was not done on low risk population it is difficult to comment on the test performance of the combined use of PAPP-A and uterine A PI for screening for adverse pregnancy outcome. For wider clinical application of the tests however, it is essential to have uniform methodologies with consensus on the ideal POG for screening with doppler studies, on the doppler indices to be used, cut-off to be used, period of gestation for estimating PAPP-A levels and expression of the results in uniform units.

Measures should be taken to arrive at global consensus on above parameters and steps taken for their uniform application. This will facilitate the comparison of the test with each other and the results can be interpreted easily 
and accurately for which however, further research is required in future.

The study was done in a small number of patients who are already at high risk so the values cannot be applied to general population.

\section{CONCLUSION}

From the results of the present study it was concluded that when high risk patients are screened for adverse pregnancy outcome, either PAPP-A alone or Uterine Artery PI alone can be used as both the tests have good sensitivity and negative predictive value. Therefore, when a high risk patient presents in the first trimester of pregnancy she can be screened for adverse pregnancy outcome by estimating serum PAPP-A levels. She should be again screened at 20weeks of pregnancy with Uterine artery PI, especially if the PAPP-A levels done earlier are abnormal, as the combined use of both first trimester PAPP-A and second trimester Uterine Artery PI increases further the sensitivity and negative predictive value of the test, for adverse pregnancy outcome, over that of either test when used alone. If however the patient reports for the first time in second trimester of pregnancy, Uterine artery Doppler and estimation of its PI should be done to determine her risk for adverse pregnancy outcome. Those women who have any test result that is abnormal at any time, should be followed meticulously to prevent maternal and perinatal morbidity.

\section{Merits of the study}

While most of the studies done previously concentrate on the relation between PAPP-A and Ut. artery doppler and hypertensive disorders and growth restriction this study also sees the relation with other adverse pregnancy outcomes. In most of the previously done studies the PAPP-A values are expressed as MOMs while in the present study we have also given the absolute values.

\section{ACKNOWLEDGMENTS}

All the authors have contributed equally in the study.

Funding: No funding sources

Conflict of interest: None declared

Ethical approval: The study was approved by the Institutional Ethics Committee Human Research, Lady Hardinge Medical College and Associate hoapital, New Delhi. (LHMC/ECHR/2014/564)

\section{REFERENCES}

1. Hajo IJ. Wildschut, Constitutional and environmental factors leading to a high-risk pregnancy. Chapter 1 in David K. James book of high risk pregnancy: management options, Saunders company 3rd edition, page no. 11 .
2. Sciscione AC, Hayes EJ. Uterine artery Doppler flow studies in obstetric practice. A Journal of Obst and Gynecol. 2009;121-5.

3. Mcleod L. How useful is uterine artery Doppler ultrasonography in predicting pre-eclampsia and intrauterine growth restriction? CMAJ. 2008;178(6):727-9

4. Irwin JC, Suen L-F, Martina NA, Mark SP and Guidice LC. Role of the IGF system in the trophoblast invasion and pre-eclamsia. Human Reproduction. 1999;14(2):90-6.

5. Fialova L, Malbohan IM. Pregnancy-associated plasma protein A (PAPP-A): theoretical and clinical aspects. BratislLekListy. 2002;103(6):194-205.

6. Pilalis A, Souka AP, Antsaklis P, Daskalaki G, Papantoniou N, Mesogitis S, et al. Screening for preeclampsia and fetal growth restriction by uterine artery Doppler and PAPP-A at 11-14 wks' gestation. Ultrasound Obstet Gynecol. 2007;29:135-40.

7. Spencer K, Cowans NJ, Chefetz I, Tal J and Meiri H. First-trimester maternal serum PP-13,PAPP-A and second-trimester uterine artery Doppler pulsatility index as markers of preeclampsia. Ultrasound and Gyanecol. 2007;29:128-34.

8. Aardema MW, Saro MCS, Lander M, De Wolf BTHM, Oosterhof $\mathrm{H}$ and Aarnoudse JG. Second trimester Doppler ultrasound screening of the uterine arteries differentiates between subsequent normal and poor outcomes of hypertensive pregnancy: two different pathophysiological entities? Clinical Science. 2004;106:377-82.

9. Poon LCY, Stratieva V, Piras S, Piri S and Nicolaides KH. Hypertensive disorders in pregnancy: combined screening by uterine artery Doppler, blood pressures and serum PAPP-A at 11-13 weeks. Prenatal Diagnosis. 2010;30:216-23.

10. Albaiges G, Missflder-Lobos H, Lees C, Parra M and Nicolaides. One Stage Screening for Pregnancy Complications by Color Doppler Assessment of the Uterine Arteries at 23 Weeks' Gestation. Obstet and Gynecol. 2000;96:559-64.

11. Albaiges G, Missfelder-Lobos H, Parra M, Lees C, Cooper D and Nicolaides KH. Comparison of color Doppler uterine artery indices in a population at high risk for adverse outcome at 24 weeks' gestation. Ultrasound Obstet Gynecol. 2003;21:170-3.

12. Lees C, Parra M, Missfelder-Lobos H, Morgans A, Fletcher $\mathrm{O}$ and Nicolaides KH. Individualized Risk Assessment for Adverse Pregnancy Outcome by Uterine Artery Doppler at 23 Weeks. Obst and Gynecol. 2001;98(3):369-73.

13. Yu CK, Khouri, O, Onwudiwe N. Spilliopoulos Y and Nicolaides KH. Prediction of the preeclampsia by uterine artery Doppler imaging: relationship to the gestational age at delivery and small for gestational age. Ultrasound Obstet gyanecol. 2008;31:310-3.

14. Spencer K, Cowans NJ, Nicolaides KH. Low levels of maternal serum PAPP-A in the first trimester and the risk of pre-eclampsia. Prenatal Diagnosis. 2008;28:7-10. 
15. Kumar M, Sharma K, Singh R, Singh S. Role of maternal factors, PAPP-A and Doppler in screening for early-and late-onset pregnancy hypertension in Asian population. Hypertension in pregnancy. 2016;35(3):382-93.
Cite this article as: Kaundal A, Gupta U,

Bhattcharjee J. Role of pregnancy associated plasma protein-A and doppler velocimetry in the assessment of fetomaternal outcome in high risk pregnancy. Int J Reprod Contracept Obstet Gynecol 2019;8:1981-9. 